\title{
Effects of chlortetracycline and copper on tetracyclines and copper resistance genes and microbial community during swine manure anaerobic digestion
}

\author{
Rui Wang ${ }^{\mathrm{a}, \mathrm{b}, 1}$, Meixue Chen ${ }^{\mathrm{a}, \mathrm{b}, 1}$, Feng Feng ${ }^{\mathrm{c}}$, Junya Zhang $^{\mathrm{a}, \mathrm{b}}$, Qianwen Sui ${ }^{\mathrm{a}, \mathrm{b}}$, Juan Tong ${ }^{\mathrm{a}, \mathrm{b}}$, \\ Yuansong Wei ${ }^{\mathrm{a}, \mathrm{b}, \mathrm{d}, *}$, Dongbin Wei ${ }^{\mathrm{a}}$ \\ ${ }^{a}$ State Key Joint Laboratory of Environmental Simulation and Pollution Control, Research Center for Eco-Environmental Sciences, Chinese Academy of Sciences, Beijing 100085, \\ PR China \\ ${ }^{\mathrm{b}}$ Department of Water Pollution Control Technology, Research Center for Eco-Environmental Sciences, Chinese Academy of Sciences, Beijing 100085, PR China \\ ${ }^{\mathrm{c}}$ Chinese Academy of Inspection and Quarantine, Beijing 100176, PR China \\ ${ }^{\mathrm{d}}$ University of Chinese Academy of Sciences, Beijing 100049, PR China
}

\section{H I G H L I G H T S}

- The predominant ARGs could be effectively reduced through mesophilic anaerobic digestion.

- Microbial community evolution was the main driver to the change of ARGs.

- Addition of CTC, $\mathrm{Cu}$ and CTC + Cu affected microbial community change and hindered removal of ARGs.

- Treponema might indicate the end of anaerobic digestion and compete with ARGs host bacteria.

- CTC + Cu seriously affected Treponema and ARGs during anaerobic digestion.

\section{G R A P H I C A L A B S T R A C T}

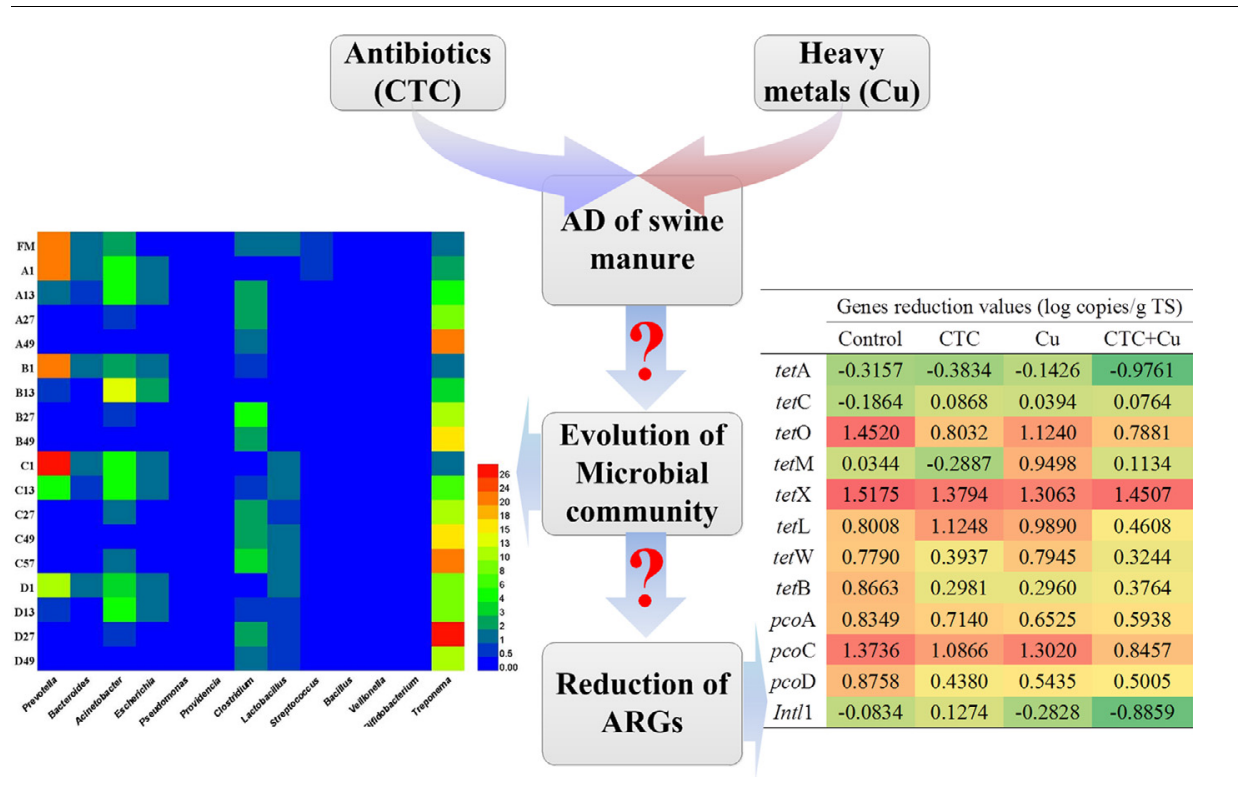

A B S T R A C T

As antibiotic and heavy metals are over used in the livestock industry, animal manure is a reservoir of antibiotic resistance genes (ARGs). Anaerobic digestion has been reported to have the potential to reduce ARGs. However, few studies investigated whether reduction of ARGs would be affected by different external pressures including antibiotics and heavy metals during anaerobic digestion. The purpose of this study was thus to investigate effects of both chlortetracycline (CTC) and Cu on reduction of ARGs, heavy metal resistance genes (HMRGs) and mobile genetic elements (MGEs) during the swine manure

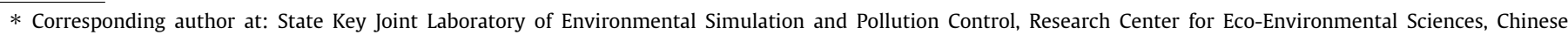
Academy of Sciences, Beijing 100085, PR China.

E-mail address: yswei@rcees.ac.cn (Y. Wei).

1 These authors contributed equally to this work.
} 
Keywords:

ARGs

HMRGs

MGEs

Swine manure

Anaerobic digestion anaerobic digestion. The results showed that the predominant $\mathrm{ARGs}$ (tetO, tetW, tetX, tet $\mathrm{L}$ ) could be effectively reduced (approximately $1.00 \mathrm{log}$ copies/g TS) through mesophilic anaerobic digestion. Microbial community evolution was the main driver. It was interesting that Treponema might indicate the termination of anaerobic digestion and compete with ARGs host bacteria. Addition of CTC, $\mathrm{Cu}$ and CTC + Cu affected microbial community change and hindered removal of ARGs, especially, CTC + Cu seriously affected Treponema and ARGs during anaerobic digestion.

(C) 2017 Elsevier Ltd. All rights reserved.

\section{Introduction}

The increasing emergence and spread of antibiotic resistance has been considered to be one of the most serious public health issues and attracted more and more attention in the recent years. It has been estimated that antibiotic resistance is responsible for more than 25,000, 23,000, and 38,000 deaths every year in the European, the United States, and Thailand, respectively (Björn Berglund, 2015). Due to overuse of antibiotics as feed additives to control and prevent diseases, and to promote growth in concentrated livestock and poultry industry (Kemper, 2008; Koike et al., 2007; Sarmah et al., 2006), antibiotic resistant bacteria (ARB) and antibiotic resistance genes (ARGs) could be induced under the selective pressure of antibiotics in animal intestinal tract or outer environment, resulting in animal manure being a reservoir of ARB and ARGs (Heuer et al., 2011; Mackie et al., 2006). One important cause of the proliferation of ARGs is the horizontal gene transfer (HGT) with mobile genetic elements (MGEs) as vectors, which have specific structures and ability to capture genes by a sitespecific recombination system. Integrons are a kind of MGEs linked with multidrug resistance and facilitate ARGs dissemination (Molla et al., 2007). Some bacteria can capture ARGs housed on the MGEs via HGT (Martinez, 2008) and Martinez et al. (2014) ranked the ARGs which could transfer by MGEs harbored in human bacteria pathogens as the highest risk level.

Tetracyclines (TCs) are broad-spectrum antibiotics, which are extensively used in the livestock industry (Kumar et al., 2005; Sarmah et al., 2006). Tetracycline resistance genes have been reported ubiquitous occurrence in the environments surrounding a pig farm (Wu et al., 2010). Currently, more than 40 classes of tetracycline resistance genes (tet) have been described and studied, including three resistance mechanisms (efflux pump proteins, ribosomal protection proteins (RPPs), and inactivating enzymes) (Roberts, 2005). Tetracycline resistance has already emerged in many commensal and pathogenic bacteria because of tet genes acquisition (Chopra and Roberts, 2001). Additionally, copper is usually cooperated with antibiotics to enhance their effects in the intensive livestock production (Nicholson et al., 1999). There is growing concern that heavy metals, such as copper, function as a selective agent in the proliferation of ARGs through coselection (Baker-Austin et al., 2006). The co-occurrence of antibiotic and metal resistance in bacteria has been widely observed due to the cross- or co-resistance phenomena (Pal et al., 2015). Cross-resistance occurs when the same mechanism reduces the susceptibility to metals and antibiotics simultaneously, and coresistance occurs when separate resistance genes are situated on the same genetic element (Pal et al., 2015).

The previous studies investigated that tet genes (such as tetX, tet $\mathrm{O}$, tet $\mathrm{W}$ ) were the predominant genes in the swine manure (Wang et al., 2016) and the wastewater of swine farm (Sui et al., 2016). Anaerobic digestion has been frequently reported to have the potential to reduce ARGs, e.g., LaPara and Diehl (2010) reported that five tet (tetA, tetL, tetO, tet $\mathrm{W}$, tet $\mathrm{X}$,) and intl 1 genes decreased during the anaerobic digestion, and removal efficiencies of tet and intl1 genes increasing as a function of temperature; additionally, hydraulic retention time might have an influence on reduction of ARGs. Wu et al. (2016) reported that the acidogenic phase of thermophilic digestion was mainly responsible for reducing the ARGs, such as tetA, tetG, tetX, sul1, ermB, dfrA1, dfrA2 and intI1, while the subsequent methanogenic phase caused a rebound in their quantity; thermophilic digestion could effectively decrease the ARGs and mesophilic one could barely reduce the ARGs. In the study of Sui et al. (2016), mesophilic anaerobic digestion obviously reduced the ARGs and the reduction efficiency was improved by stable operational temperature and longer solid retention time (SRT). However, few studies investigated whether reduction efficiencies of ARGs, as well as HMRGs and MGEs would be affected by different external pressures (including antibiotics and heavy metals) during anaerobic digestion.

Thus the purpose of this study was to investigate effects of both chlortetracycline (CTC) and $\mathrm{Cu}$, which are extensively used in swine productions, on ARGs, HMRGs and MGEs during the swine manure anaerobic digestion through batch experiments in order to better control the risk from ARGs, HMRGs and MGEs in animal manure spreading to the environment.

\section{Materials and methods}

\subsection{Anaerobic digestion setup}

Swine manure was collected from a concentrated pig farm located in eastern of Beijing, China. Inoculum sludge was collected from egg-shaped anaerobic digesters of Xiaohongmen municipal wastewater treatment plant (WWTP) in Beijing, China, treating municipal wastewater with the designed capacity of $600,000 \mathrm{~m}^{3} /$ $\mathrm{d}$, and sludge after setting down for ca. 3-5 days was used for inoculum. The characteristics of raw materials were listed in Table 1.

Anaerobic digestion tests were carried out by an Automatic Methane Potential Test System II (Bioprocess Control, Sweden) including a series of serum bottles (total volume: $2 \mathrm{~L}$; working volume: $1.7 \mathrm{~L}$ ) and plastic caps equipped with agitators and rubber stoppers. Swine manure slurry and inoculums were transferred to each reactor at ratio of $1: 1(v / v)$, while CTC and $\mathrm{Cu}$ were spiked in the reactors in the form of solution in order to determine their influence on ARGs, respectively. Four anaerobic digesters were set up including reactor $\mathrm{A}$ (control) without spiked CTC and $\mathrm{Cu}, \mathrm{B}$ (spiked CTC at $500 \mathrm{mg} / \mathrm{kg} \mathrm{DW}$ ), C (spiked Cu at 5,000 $\mathrm{mg} / \mathrm{kg} \mathrm{DW}$ ) and D (spiked CTC at $500 \mathrm{mg} / \mathrm{kg} \mathrm{DW}$ and $\mathrm{Cu}$ at 5,000 $\mathrm{mg} / \mathrm{kg} \mathrm{DW}$ ). Spiked concentrations of CTC and $\mathrm{Cu}$ were according to their concentration residues in the swine manure (Table 1 ).

After sealing each reactor, the headspaces were flushed with nitrogen gas for 2 min to remove traces of oxygen. Then the reactors were incubated in a water bath at $37 \pm 1^{\circ} \mathrm{C}$. The termination of anaerobic digestion was judged by no obvious biogas production from reactors (daily biogas production $<2 \mathrm{~mL}$ ). Biogas production yields could be automatically measured by the AMPTS II with displacement of water. Meanwhile, biogas was sampled on day 1,2, 3, $6,8,10,13,15,17,20,22,24,27,29,31,34,36,38,41,49,52$ and 57 for biogas composition analysis, respectively. The mixed slurries 
Table 1

Characteristics of raw materials in the swine manure anaerobic digestion.

\begin{tabular}{llll}
\hline Characteristics & Swine slurry & Inoculum & Mixture \\
\hline $\mathrm{pH}$ & $6.72 \pm 0.14$ & $7.48 \pm 0.24$ & $7.17 \pm 0.25$ \\
Moisture (\%) & $95.14 \pm 1.25$ & $98.82 \pm 0.44$ & $96.68 \pm 0.53$ \\
$\mathrm{TS}^{\mathrm{a}}(\%)$ & $4.86 \pm 0.34$ & $1.18 \pm 0.08$ & $3.32 \pm 0.84$ \\
$\mathrm{VS}^{\mathrm{b}}(\%)$ & $3.95 \pm 0.87$ & $0.68 \pm 0.07$ & $2.50 \pm 0.24$ \\
$\mathrm{EC}(\mathrm{mS} / \mathrm{cm})$ & $6.65 \pm 1.34$ & $3.46 \pm 0.91$ & $4.47 \pm 0.61$ \\
$\mathrm{Cu}(\mathrm{mg} / \mathrm{kg} \mathrm{DW})$ & $538.75 \pm 29.93$ & - & - \\
Chlortetracycline $(\mathrm{mg} / \mathrm{kg} \mathrm{DW})$ & $146.07 \pm 7.32$ & - & - \\
Tetracycline (mg/kg DW) & $12.31 \pm 0.66$ & - & - \\
Oxytetracycline (mg/kg DW) & $1.11 \pm 0.05$ & - & - \\
\hline
\end{tabular}

a Total solids.

b Volatile solids.

in each reactor were sampled on day 1,6,13, 20, 27, 34, 49 and 57, respectively, for DNA extraction and analysis of $\mathrm{pH}$, soluble chemical oxygen demand (SCOD), volatile fatty acids (VFAs) (Support Information).

The accumulative volume of biogas produced $\left(P_{\text {biogas }}(t)\right)$ over the time course during the batch tests was fitted with the modified Gompertz equation (Zhang et al., 2014):

$P_{\text {biogas }}(\mathrm{t})=P \cdot \exp \left[-\exp \left(\frac{R_{m} * \mathrm{e}}{P}(\lambda-\mathrm{t})+1\right)\right]$

where $P$ is the biogas potential ( $\mathrm{mL}$ ), $R_{m}$ is the maximum biogas production rate ( $\mathrm{mL} /$ day), $\lambda$ is the lag phase time (day), and $\mathrm{e}$ is the exp $(1)=2.7183$.

\subsection{Genomic DNA extraction}

Anaerobic digestion slurry was sampled $5 \mathrm{~mL}$ from each digester on 1st, 6th, 13th, 20th, 27th, 34th, 49th, (57th for C digester) in triplicate by syringe, respectively, and centrifuged at $4,000 \mathrm{rpm}$ for $10 \mathrm{~min}$. The solid evenly $0.2 \mathrm{~g}$ was transfer to a $2 \mathrm{~mL}$ sterilized tubes for total DNA extraction with QIAamp DNA Stool Mini Kit (QIAGEN; Solon, OH) according to manufacturer's instructions. The concentration and quality of the extracted DNA was determined by a NanoDrop 1000 spectrophotometer analysis (NanoDrop, USA) and $1.5 \%(w / v)$ agarose gel eletrophoresis. DNA extractions were stored at $-20^{\circ} \mathrm{C}$ for the further analysis.

\subsection{Quantitative real time $P C R$}

Quantitative real time PCR ( $\mathrm{qPCR}$ ) was used to quantify the absolute abundance of eight tetracycline resistance genes (efflux pump: tet $\mathrm{A}$, tetB, tet $\mathrm{C}$, tet $\mathrm{L}$; ribosomal protection protein: tetO, tet $\mathrm{M}$, tet $\mathrm{W}$; enzymatic modification: tet $\mathrm{X}$ ), the three copper resistance genes ( $p c o \mathrm{~A}, p c o \mathrm{C}$ and $p c o \mathrm{D})$, the integrase gene of class 1 integrons (intI1) and the 16S rRNA gene. Primers are described in the Supporting Information (Table S1).

The qPCR analysis was conducted using an ABI7300 apparatus (ABI, USA). Each qPCR run consisted of 2 min initial denaturation at $95{ }^{\circ} \mathrm{C}$, followed by 40 cycles of denaturation at $95^{\circ} \mathrm{C}$ for $10 \mathrm{~s}$, and anneal and extended at $60^{\circ} \mathrm{C}$ for $40 \mathrm{~s}$. A $20 \mu \mathrm{L}$ reaction mixture contained $10 \mu \mathrm{L}$ of $2 \times$ Power SybrGreen qPCR Master Mix (Applied Biosystems, USA), $0.5 \mu \mathrm{L}$ of forward and reverse primers $(10 \mu \mathrm{M})$, $2 \mu \mathrm{L}$ of template DNA and $7 \mu \mathrm{L}$ of $\mathrm{dd}_{2} \mathrm{O}$. Samples were analyzed in triplicate independent qPCR runs, with a standard curve and negative control included in each run. The quantity of target DNA in unknown samples was calculated based on a standard curve generated using known quantities of template DNA. Standards for qPCR were prepared by PCR amplification of genes from positive controls, followed by ligation into pMD-18T cloning vector following manufacturer's instructions (Takara), and transformation into JM109 Escherichia coli (Takara). Plasmids were purified using
SK1191 UNIQ-10 kit (Sangon Biotech, Shanghai, Co., Ltd. CN). 10fold serial dilutions $\left(10-10^{8}\right)$ of plasmid DNA were prepared and run on the thermal cycler to generate standard curves $\left(R^{2}>0.99\right)$. Following qPCR, melting curves were generated automatically to verify that nonspecific amplification did not occur. DNA copy concentrations (copies $/ \mu \mathrm{L}$ ) were calculated by the following formula.

DNA copy concentration (copies $\mu \mathrm{L}^{-1}$ )

$$
=\frac{\text { DNA mass concentration }\left(\mathrm{ng} \mu \mathrm{L}^{-1}\right)}{\text { DNA molecular weight }\left(\mathrm{g} \mathrm{mol}^{-1}\right)} \times 6.02 \times 10^{23} \times 10^{-9}
$$

Gene quantities are presented on a per gram anaerobic digestion materials total solid (TS) basis because the total quantity of genes are of greatest importance (absolute abundance).

\subsection{High-throughput sequencing and bioinformatics analysis}

DNA extractions of fresh swine manure and samples on days 1 , $13,27,49$ (day 57 only for $C$ test) of the swine manure anaerobic digestion, respectively, were used to determine the microbial community analysis using PCR primers 515F (GTGCCAGCMGCCGCGGTAA) and 806R (GGACTACHVGGGTWTCTAAT) targeting the bacteria 16S V4 region according to the protocol described in Caporaso et al. (Caporaso et al., 2010). PCR amplicons were further purified with a DNA purification kit (BioFlux, Japan), and concentrations were determined using spectrometry NanoDrop1000 (Thermo Scientific, USA). Amplicons from different samples were then mixed to achieve equal mass concentrations in the final mixture, which were sent out to Novogene Co., Ltd. in Beijing for small-fragment library construction and pair-end sequencing using Illumina MiSeq sequencing system (Illumina, USA).

Sequencing reads from the original DNA fragments were merged using FLASH and then filtered by QIIME quality filters (Caporaso et al., 2010). PCR chimeras were filtered out using UCHIME (Edgar et al., 2011). And then the reads are "clean reads". The average length of all the clean reads was $253 \mathrm{bp}$, and the minimum number of selected sequences in the 18 samples was 15,218 for bacterial community analysis. To fairly compare the 18 samples at the same sequencing depth, normalization of the sequence number was conducted by extracting the first 15,218 sequences in each sample for bacterial community analysis. And all the normalized sequences were uploaded to MG-RAST (http://metagenomics. anl.gov/, No. project was 10976). Taxonomic classification of the sequences of each sample was carried out individually using the RDP Classifier. A bootstrap cutoff of $50 \%$ suggested by the RDP was applied to assign the sequences to different taxonomy levels (Zhang et al., 2016).

\subsection{Data analysis}

Statistical calculations and data analysis were performed using the SPSS 16.0 statistical software package (IBM, USA) and Origin 9.0 (Origin Lab, USA). A heat map of the top 24 families in each sample was built using HemI (http://hemi.biocuckoo.org/). According to the relative content of each family based on the classification, a principal component analysis (PCA) was performed using Canoco 5.0 (Microcomputer Power, USA).

\section{Results and discussion}

\subsection{Performance of anaerobic digestion}

The durations of the four anaerobic digestion tests were totally different (Table 2). Although the control one lasted for 37 days, the biogas yield had already arrived at $95 \%$ of the total yield on 21 th 
Table 2

Estimated values of parameters in the Modified Gompertz Equation for swine manure anaerobic digestion.

\begin{tabular}{|c|c|c|c|c|c|c|}
\hline $\begin{array}{l}\text { Anaerobic } \\
\text { digestion tests }\end{array}$ & $\begin{array}{l}\text { Total reaction time } \\
\text { (days) }\end{array}$ & $\begin{array}{l}\text { The lag phase time } \\
\lambda \text { (day) }\end{array}$ & $\begin{array}{l}\text { The biogas potential } \\
P(\mathrm{~mL})\end{array}$ & $\begin{array}{l}\text { The maximum biogas production rate } \\
R_{m} \text { (mL/day) }\end{array}$ & $\mathrm{R}^{2}$ & $\begin{array}{l}\text { Biogas yield comparing with } \\
\text { control }(\%)\end{array}$ \\
\hline A & 37 & 0.3 & 9445.53 & 1506.56 & 0.99 & 0 \\
\hline B & 55 & 0.1 & 11974.30 & 978.06 & 0.98 & 26.77 \\
\hline$C$ & 55 & 2.5 & 12587.55 & 771.41 & 0.99 & 33.26 \\
\hline $\mathrm{D}$ & 32 & 0 & 6540.34 & 1137.69 & 0.99 & -30.75 \\
\hline
\end{tabular}

A: Control test; B: CTC spiked test; C: Cu spiked test; D: CTC+Cu spiked test.

day. Actually, the whole anaerobic digestion could divide into two stages: increment stage and plateau stage, approximately $95 \%$ of the total biogas was produced at the increment stage. The biogas production was fitted using the modified Gompertz equation (Table 2). The maximum biogas production rate $\left(R_{m}\right)$ somehow reflects the reaction rate of anaerobic digestion, including organic matter degradation and methane production rate.

The lag phase time $(\lambda)$ in the $\mathrm{Cu}$ spiked test $(C)$ was much higher $(\lambda=2.5)$ than that in the others $(A=0.3 ; B=0.1 ; D=0)$ tests, and the maximum biogas production rate $\left(R_{m}\right)$ in $C$ test was much lower $(771.41 \mathrm{~mL} /$ day) than that in the others (Table 2.). These results implied that $\mathrm{Cu}$ at this level had a significant influence on the biogas production rate of anaerobic digestion. However, the biogas potential in the $C$ test was the highest $(12587.55 \mathrm{~mL})$ among the four tests, which was 33\% more than that in the control. This fact might indicate that although $\mathrm{Cu}$ addition inhibited the biogas production rate, it increased the biogas potential. On the contrary, the biogas potential in the D test was the lowest $(6540.34 \mathrm{~mL})$, which was $30 \%$ less than the control one, but its maximum biogas production rate was much higher $(1137.69 \mathrm{~mL} /$ day $)$ than that in the $B(978.06 \mathrm{~mL} /$ day $)$ or $\mathrm{C}(771.41 \mathrm{~mL} /$ day $)$ test, lower than that in the $\mathrm{A}(1506.56 \mathrm{~mL} /$ day) test. This fact indicated that $\mathrm{Cu}$ and CTC addition together decreased the total biogas yield, and inhibited $R_{m}$, but $R_{m}$ in the $\mathrm{D}$ was much higher than that in the $\mathrm{B}$ or $\mathrm{C}$ test. These results demonstrated that adding CTC, Cu separately would seriously slow down the reaction rate but increase the biogas potential; adding CTC $+\mathrm{Cu}$ together would decrease the biogas potential and the reaction rate, to some extent, impede the anaerobic digestion.

\subsection{Effects of CTC, $\mathrm{Cu}$ and $C T C+C u$ on reduction of $A R G s, H M R G s$ and $M G E$}

3.2.1. Reductions of ARGs, HMRGs, MEG in anaerobic digestion

The absolute abundance of all the ARGs (including eight tet genes), HMRGs (including three pco genes) and MGE (including

Table 3

ARGs reduction of $\mathrm{A}, \mathrm{B}, \mathrm{C}$ and $\mathrm{D}$ tests by the swine manure anaerobic digestion.

\begin{tabular}{|c|c|c|c|c|}
\hline \multirow{2}{*}{ ARGs, HMRGs, MGEs } & \multicolumn{4}{|c|}{ Genes reduction values (log copies/g TS) } \\
\hline & Control & CTC & $\mathrm{Cu}$ & $\mathrm{CTC}+\mathrm{Cu}$ \\
\hline tet $\mathrm{A}$ & -0.3157 & -0.3834 & -0.1426 & -0.9761 \\
\hline tet $\mathrm{C}$ & -0.1864 & 0.0868 & 0.0394 & 0.0764 \\
\hline tet $\mathrm{O}$ & 1.4520 & 0.8032 & 1.1240 & 0.7881 \\
\hline tet $\mathrm{M}$ & 0.0344 & -0.2887 & 0.9498 & 0.1134 \\
\hline tet $\mathrm{X}$ & 1.5175 & 1.3794 & 1.3063 & 1.4507 \\
\hline tet $\mathrm{L}$ & 0.8008 & 1.1248 & 0.9890 & 0.4608 \\
\hline tet $\mathrm{W}$ & 0.7790 & 0.3937 & 0.7945 & 0.3244 \\
\hline tet $\mathrm{B}$ & 0.8663 & 0.2981 & 0.2960 & 0.3764 \\
\hline pcoA & 0.8349 & 0.7140 & 0.6525 & 0.5938 \\
\hline pcoC & 1.3736 & 1.0866 & 1.3020 & 0.8457 \\
\hline pcoD & 0.8758 & 0.4380 & 0.5435 & 0.5005 \\
\hline Intl 1 & -0.0834 & 0.1274 & -0.2828 & -0.8859 \\
\hline $16 \mathrm{~S}$ rRNA & 0.4932 & 0.2652 & 0.3808 & 0.2676 \\
\hline
\end{tabular}

This table is red-yellow-green color gradation table, the red color means higher value and the green color means lower value. 
one intI1 genes) in the fresh swine manure were higher (approximately 0 to $3 \log$ copies/g TS) than those in the inoculum from WWTP (Fig. S2). It was obvious that the dominant genes between the fresh swine manure and the inoculum from WWTP were totally different (Fig. S2 b, c); e.g., relative abundance of tet genes in the fresh swine manure $(6.20 \%)$ was much higher than that in the inoculum $(0.96 \%)$; tet $\mathrm{W}$, tet $\mathrm{X}$, tet $\mathrm{O}$, tet $\mathrm{L}$ dominated evidently in the fresh swine manure. These results illustrated that tetracycline resistance existed abundantly in the swine manure. Relative abundance of intI1 gene was dominant in the inoculum, which was much higher $(0.93 \%)$ than that in the fresh swine manure $(0.12 \%)$. Additionally, tetA, tetC showed relative high levels in the inoculum.

On the whole, most of the tet, pco and intI1 genes showed decreasing trends among the four anaerobic digestion, e.g., especially the dominant ARGs in the swine manure, such as tet $\mathrm{W}$, tetX, tetO, tet $\mathrm{L}$, were almost reduced by one order of magnitude (Table 3 ). The reduction of tetX was the largest among all the ARGs, which was decreased by $1.52,1.38,1.31,1.45 \log$ copies/g TS in the control, $\mathrm{CTC}, \mathrm{Cu}$ and $\mathrm{CTC}+\mathrm{Cu}$ spiked tests, respectively. The three pco genes decreased obviously and were reduced by approximately one order of magnitude as well at the end of the anaerobic digestion (Table 3 ). However, tetA and intI 1 showed obviously increasing trends during the anaerobic digestion; and tetC and tetM were barely reduced, even increased in the control (tetC) and the CTC (tetM) tests. However, in the Cu test, tetM was almost reduced by one order of magnitude, this indicate that $\mathrm{Cu}$ might affect tetM evolution. It should pay more attention to tetA, tetC, tet $\mathrm{M}$ and intI1, which were hard to be reduced by the anaerobic digestion process. These results were opposite to results of the research (LaPara and Diehl, 2010), which demonstrated that tetA and intl1 could be effectively removed from the municipal wastewater solids and decreased by more than one order of magnitude at the end of the $37^{\circ} \mathrm{C}$ mesophilic anaerobic digestion. Sui et al. (2016) investigated the distribution of ARGs in swine wastewater anaerobic digestion and the results showed that tetX was effectively removed but intl 1 was barely reduced after the mesophilic anaerobic digestion. These reduction differences of intl 1 and ARGs might be caused by different substrates (e.g., swine manure, sewage sludge), inoculums, or different operating conditions, and further investigation is needed.

Pearson correlations analysis among the ARGs, HMRGs, MGE and 16S rRNA genes during the swine manure anaerobic digestion were shown in Table 4, tetO, tetX, tetL, tetW and pcoA, pcoC, pcoD presented a strong positive correlation. This might be attributable to co-resistance between antibiotics and heavy metals (BakerAustin et al., 2006), e.g. the predominant ARGs showed a significant positive correlation with HMRGs (Wang et al., 2016). In addition, tet $\mathrm{A}$, tetC and int 1 presented a strong positive correlation. These results were in accordance with the PCA analysis (Fig. 4), which tetO, tetX, tet $\mathrm{L}$, tet $\mathrm{W}, p c o \mathrm{~A}, p c o \mathrm{C}, p \operatorname{coD}$ clustered as a one group and tetA, tetC, intI 1 clustered as another group; tetM separated from the others.

Horizontal gene transfer, which could be carried out by MGE such as integron1 (intI1), is a very important pathway for ARGs' proliferation, especially under certain selective pressure (Agersø and Sandvang, 2005). Integron is considered as the most common MGEs, which is reported to coexist with tet genes (such as tetA, tetC) in conjugative plasmids by which they can be easily cotransferred into recipients (Agersø and Sandvang, 2005; Liu et al., 2012). Although no tet genes have been detected in the intI1, they have been found on ISCR2 and ISCR3 (insertion sequence common region), respectively, the latter is linked to intI 1 (Toleman et al.,

Table 4

Pearson Correlations among ARGs, HMRGs, MGE, 16S rRNA genes during the swine manure anaerobic digestion $\left(\mathrm{R}^{2}\right)$.

\begin{tabular}{|c|c|c|c|c|c|c|c|c|c|c|c|c|c|}
\hline & tet $\mathrm{A}$ & tet $\mathrm{C}$ & tet $\mathrm{O}$ & tet $\mathrm{M}$ & tet $\mathrm{X}$ & tet $\mathrm{L}$ & tet $\mathrm{W}$ & tet $\mathrm{B}$ & pcoA & pcoC & pcoD & inti 1 & $16 \mathrm{~S}$ \\
\hline tetA & 1.0000 & & & & & & & & & & & & \\
\hline tet $C$ & 0.4219 & 1.0000 & & & & & & & & & & & \\
\hline tet $O$ & -0.2837 & 0.0921 & 1.0000 & & & & & & & & & & \\
\hline tet $M$ & 0.0099 & 0.2843 & 0.1412 & 1.0000 & & & & & & & & & \\
\hline tet $X$ & -0.0835 & 0.1418 & $0.7777 * *$ & -0.1300 & 1.0000 & & & & & & & & \\
\hline tetL & -0.1186 & 0.1638 & $0.7581^{* *}$ & 0.1415 & $0.8378 * *$ & 1.0000 & & & & & & & \\
\hline tet $W$ & -0.2273 & 0.1426 & $0.9316^{* *}$ & 0.3299 & $0.7156^{* *}$ & $0.8216^{* *}$ & 1.0000 & & & & & & \\
\hline $\operatorname{tet} B$ & 0.0695 & 0.4413 & $0.5866^{*}$ & 0.1460 & 0.3788 & 0.2961 & 0.4322 & 1.0000 & & & & & \\
\hline pcoA & -0.3061 & -0.0455 & $0.7878^{* *}$ & 0.0261 & $0.7107 * *$ & $0.8584^{* *}$ & $0.7930 * *$ & 0.2987 & 1.0000 & & & & \\
\hline pcoC & -0.2961 & -0.1641 & $0.8045^{* *}$ & -0.0465 & $0.8080^{* *}$ & $0.8325^{* *}$ & $0.7640^{* *}$ & 0.2263 & $0.9075^{* *}$ & 1.0000 & & & \\
\hline pcoD & -0.3387 & -0.1063 & $0.7961 * *$ & 0.1419 & $0.6642 *$ & $0.8045^{* *}$ & $0.8184 * *$ & 0.2826 & $0.9233^{* *}$ & $0.8768^{* *}$ & 1.0000 & & \\
\hline intil & $0.8006^{* *}$ & $0.6168 *$ & -0.2206 & 0.1044 & -0.1709 & -0.1248 & -0.1974 & 0.3326 & -0.2489 & -0.3636 & -0.2937 & 1.0000 & \\
\hline $16 \mathrm{~S}$ & 0.1887 & $0.5778^{*}$ & $0.6051^{*}$ & 0.4366 & 0.4912 & $0.6132 *$ & $0.6098 *$ & $0.6841^{*}$ & $0.5427^{*}$ & 0.3966 & 0.4710 & 0.3660 & 1.0000 \\
\hline
\end{tabular}

Correlation is significant at the 0.01 level $(p<0.01)$; *: Correlation is significant at the 0.05 level $(p<0.05)$.

This table is red-yellow-green color gradation table, the red color means higher value and the green color means lower value. 
2006). Liu et al. (2012) indicated that intI1 might be involved in tetA and tetC proliferation in antibiotics production wastewater treatment system. In this study, intI 1 might also play an important role on the transfer and proliferation of tet $\mathrm{A}$ and tetC, which exhibited significant positive correlations with intI1 $\left(\mathrm{R}^{2}=0.80,0.61\right.$, $p<0.05$ ) during the swine manure anaerobic digestion.

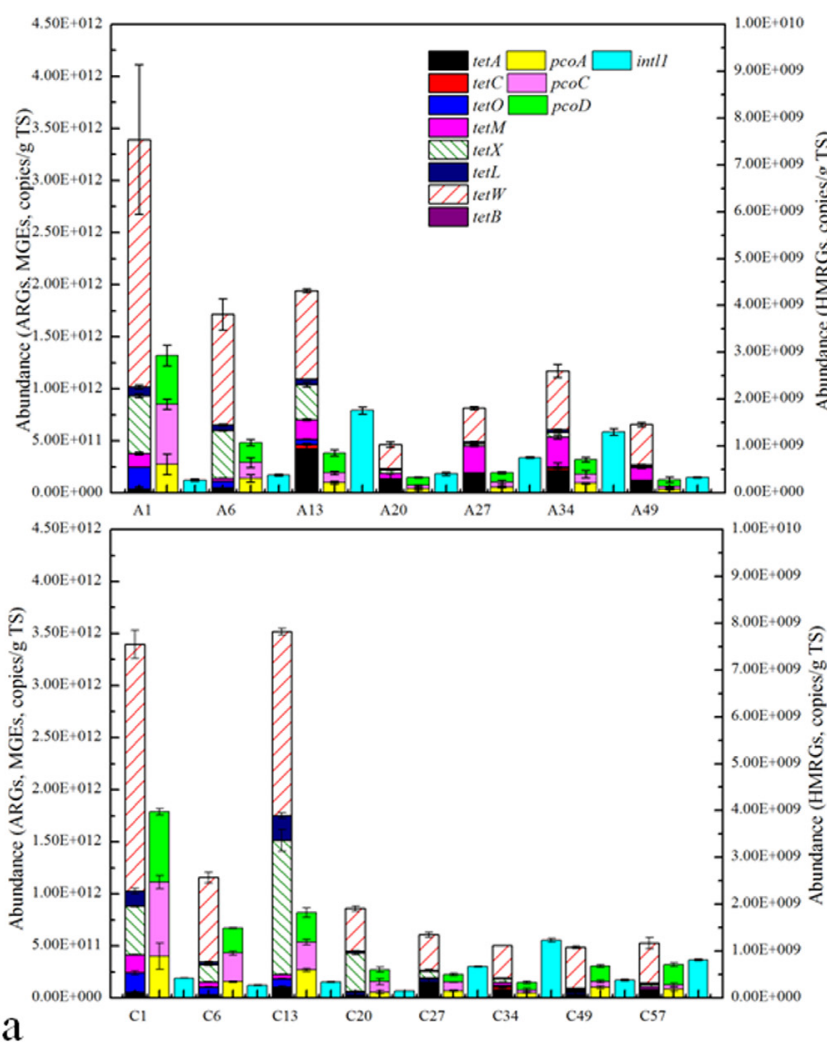

3.2.2. Effects of CTC, Cu and CTC+Cu on ARGs, HMRGs and MGE

Addition of CTC, $\mathrm{Cu}$ or CTC + Cu could impact on the reductions of ARGs, HMRGs and MGE to some extent, as well as the reductions of $16 \mathrm{~S} r$ RNA genes, e.g., the influences of CTC, $\mathrm{Cu}$ or CTC + Cu were almost negative on the removal efficiencies. The average reductions values of all the genes (including tet, pco and intI1) were

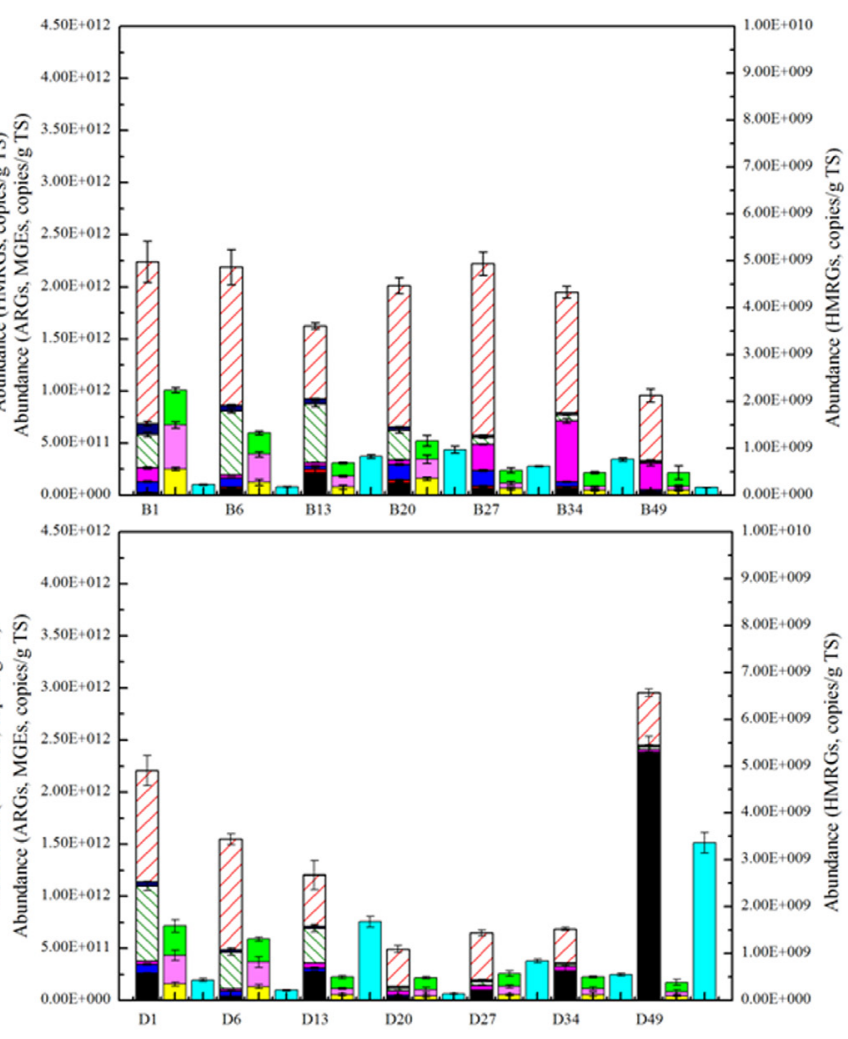

b

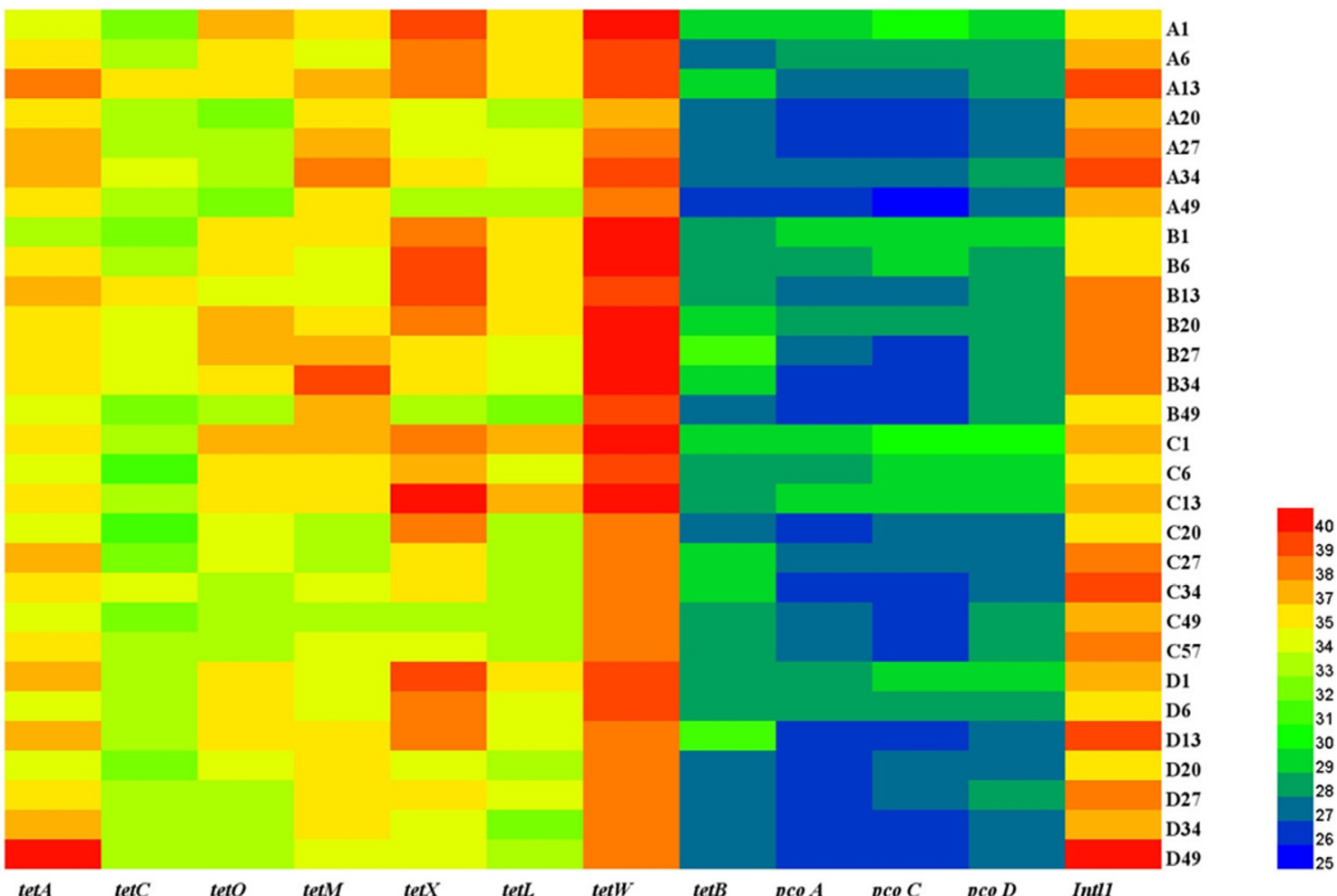

Fig. 1. Absolute abundance of ARGs, HMRGs and MGE change during the swine manure anaerobic digestion of A, B, C and D tests (a: histogram; b: heatmap). 
$0.66,0.48,0.63,0.31 \log$ copies/g TS in the control, CTC, Cu and CTC $+\mathrm{Cu}$, respectively. Evidently, the selective pressure on the $\mathrm{Cu}$ spiked test was much less than the CTC or CTC $+\mathrm{Cu}$ spiked tests, and the $\mathrm{CTC}+\mathrm{Cu}$ exerted a relative large pressure on the removal efficiencies (Table 3), especially on tetA and intI1 genes, which increased dramatically during the last few days of the anaerobic digestion. Actually, in the CTC + Cu test, all of the tet, pco and intI 1 genes showed decreasing trends until 34th day when the biogas production had already stopped (32th day). After that, tetA and intI1, which were the predominant genes in the inoculum from WWTP, increased dramatically during the last several days.

Several researchers reported that the fate and behavior of ARGs were related to microbial community evolution (Wang et al., 2016; Zhang et al., 2016). It was assumed that anaerobic digestion had the potential to remove tet, pco and intI 1 genes due to the microbial community change. In the process of anaerobic digestion, the microbial community, especially functional microorganisms, evolved little by little, and took up the ecological niche (Mei et al., 2016). Once anaerobic digestion had stopped, the functional microorganisms did not occupied the ecological niche, meanwhile other microorganisms would take it over, in which might include several host bacteria of ARGs and MEG. This might explain that the dominant genes in the inoculum, such as tetA and intI1, increased and occupied a large proportion on the 49th day of the anaerobic digestion in the CTC + Cu test (Figs.1, S3). Additionally, as mentioned above, intI1 played an important role on the proliferation of tetA under CTC $+\mathrm{Cu}$ pressure.

\subsection{Relationship among organic matters transformation, bacterial} communities and ARGs, HMRGs, MEG

\subsubsection{Organic matter transformation and ARGs, HMRGs, MEG}

Redundancy analysis (RDA) was used for analyzing the relationship between organic matter transformation (including COD, VFAs, biogas production flow rate, methane percentage) and ARGs (Fig. 4), and between bacterial communities and ARGs (Fig. 5), respectively, in order to further study driver of ARGs changes during the swine manure anaerobic digestion. All of the organic matter transformation characteristics were positively correlated with the first axis (explaining $56.34 \%$ of total variance). TCOD, SCOD, VFAs and biogas production flow rate showed a significant positive correlation with the predominant $\mathrm{ARGs}$ (tet $\mathrm{W}$, tet $\mathrm{L}$, tetO, tet $\mathrm{X}$, tet $\mathrm{B}$ ) and HMRGs (pcoA, pcoC, pcoD) which clustered together (Fig. 4). TCOD, SCOD, VFAs and biogas production flow rate represented organic matters degradation in the anaerobic digestion, which all of them were controlled by the functional bacteria. Therefore, it was reasonable that these four parameters directly or indirectly affected the variations of resistance genes.

\subsubsection{Microbial communities and ARGs, HMRGs, MEG}

Evolution of microbial community exhibited temporal variations during the swine manure anaerobic digestion among the four tests by comparing the composition and structure of bacterial $16 \mathrm{~S}$ rRNA genes (Figs. 2 and S7). Bacteroidetes (39.09\%), Proteobacteria (21.71\%) and Firmicutes (27.81\%) were the most abundant bacteria

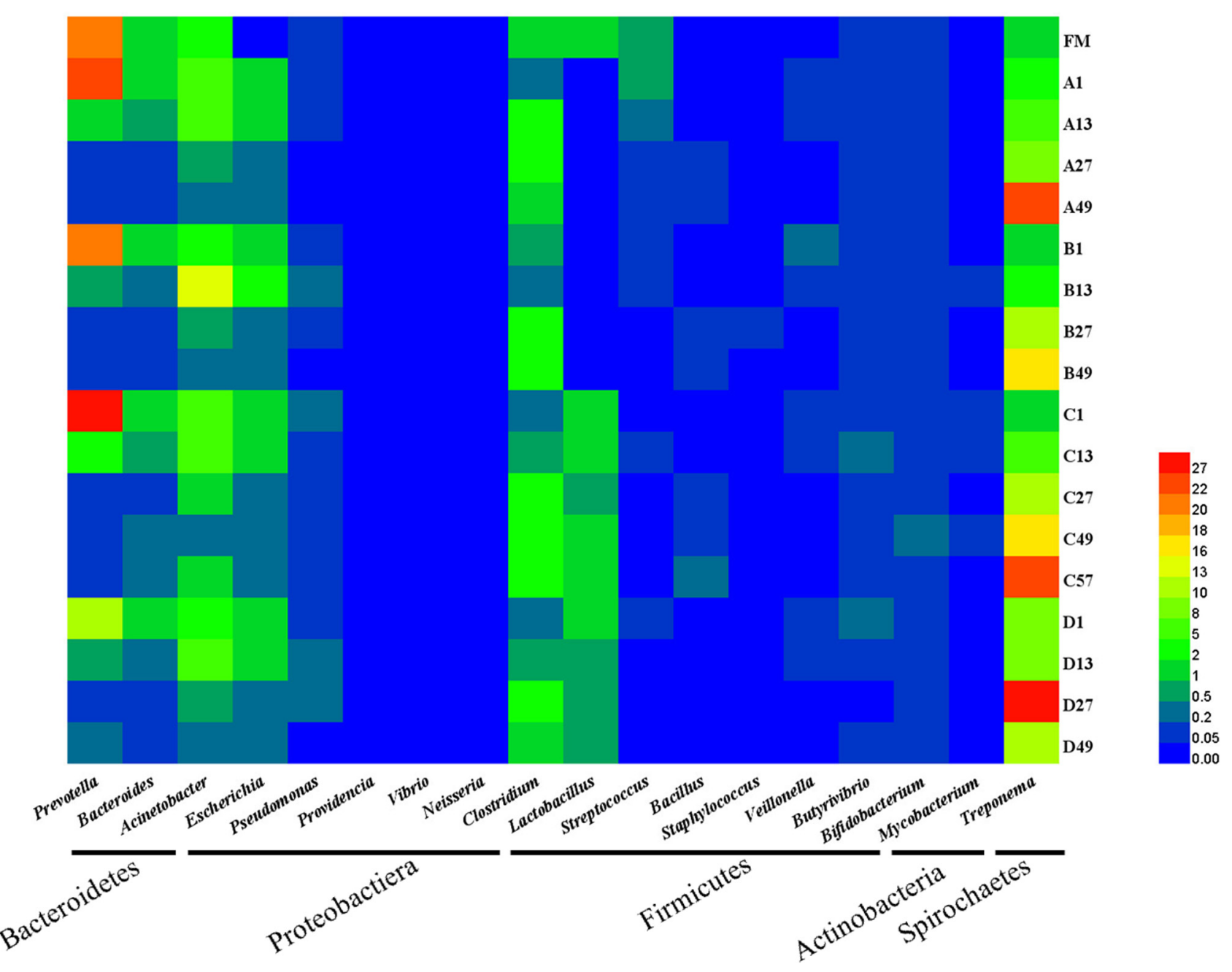

Fig. 2. Bacterial community evolution during the swine manure anaerobic digestion of A, B, C and D tests (genus). 
in the fresh swine, which accounted for approximately $90 \%$. All of them took on a decreasing trend throughout the anaerobic digestion among the four tests, which accounted for approximately $45 \%$ in the end. Spirochaetes and chloroflexi, which accounted for $1.74 \%$ and $0.24 \%$ in the fresh swine manure, increased evidently and reached to around $27 \%$ and $6 \%$ in the end of anaerobic digestion.

Pearson correlations between the most abundant microorganisms at phylum level and ARGs, HMRGs, MEG were shown in the Table S2. The predominant ARGs in the fresh swine manure such as tet $\mathrm{O}$, tet $\mathrm{X}$, tet $\mathrm{L}$, tet $\mathrm{W}$ exhibited a significant strong positive correlation with Bacteroidetes and Firmicutes, which were the most abundant bacteria in the fresh swine manure as well and might contribute to the reduction of the predominant ARGs during the anaerobic digestion. Additionally, Tenericutes showed a significant positive correlation with tetX and tetL; Proteobacteria and Verrucomicrobia showed a significant positive correlation with tetM; Euryarchaeota showed a significant positive correlation with tetA and intI1, which increased dramatically in the final few days of $\mathrm{CTC}+\mathrm{Cu}$ test (Fig. S8) and might contribute to the evidently increment of tetA and intI 1 in the end of CTC + Cu test. In other words, CTC and $\mathrm{Cu}$ spiked together might have a great influence on Euryarchaeota variation during anaerobic digestion. The Euryarchaeota are a phylum of the Archaea, which survive extreme concentrations of salt and other extremely environment. This kind of microorganism is often found in intestines (Woese et al., 1990), which explain their high levels in the fresh swine manure (Fig. S8).

However, Spirochaetes and Chloroflexi showed a significant negative correlation with most of the predominant ARGs during the swine manure anaerobic digestion (Table S2), which speculated that they might have a competitive relationship with the host bacteria of the predominant ARGs.

For detailed analysis of microbial community structure, the 18 most abundant genus (abundance above $1 \%$ in any sample) were selected and compared among the four tests (Fig. 2). The composition of microbial community binned at the genus level showed remarkable difference during the swine manure anaerobic digestion. Prevotella was the most abundant bacteria in fresh swine manure $(20.60 \%)$ and in the beginning of anaerobic digestion (A1: 22.22\%; B1: 21.48\%; C1: 27.61\%; D1: 10.35\%). Then they decreased evidently and accounted for less than 1\% (A49: $0.05 \%$; B49: 0.13\%; C57\%: 0.04\%; D49: 0.19\%) at the end of tests. Prevotella showed a significant positive correlation with the predominant ARGs (tetO, tetL, tetW) and HMRGs (pcoA, pcoC, pcoD) (Table 5, Fig. 5), which might contribute to the reductions of these resistance genes during the anaerobic digestion. When CTC and Cu were spiked together, they really inhibited Prevotella in the beginning, which the abundance (D1: $10.35 \%$ ) was around a half of the others (A1:22.22\%). The corresponding resistance genes, including tetO, tet $\mathrm{L}$, tet $\mathrm{W}$ and $p c o \mathrm{~A}, p c o \mathrm{C}, p c o \mathrm{D}$ in the $\mathrm{D}$ test were evidently less than these in the other tests on the first day (Fig. 1). Bacteroides, Veillonella showed a positive correlation with tetO, tetX, tet $\mathrm{L}$, tetW and $p c o \mathrm{~A}, p c o \mathrm{C}, p c o \mathrm{D}$, which all of them decreased among the four tests. Previous studies reported that tetracycline resistance was related to Veillonella (Olsvik et al., 1995), in this study, it might be the host bacteria of the predominant ARGs and HMRGs.

It was interesting that Treponema showed an obviously increasing trend and was the most abundant bacteria in the end of the anaerobic digestion, which accounted for $22.15 \%$, $16.09 \%, 23.76 \%, 10.56 \%$ in the control, CTC, $\mathrm{Cu}$ and CTC + Cu tests

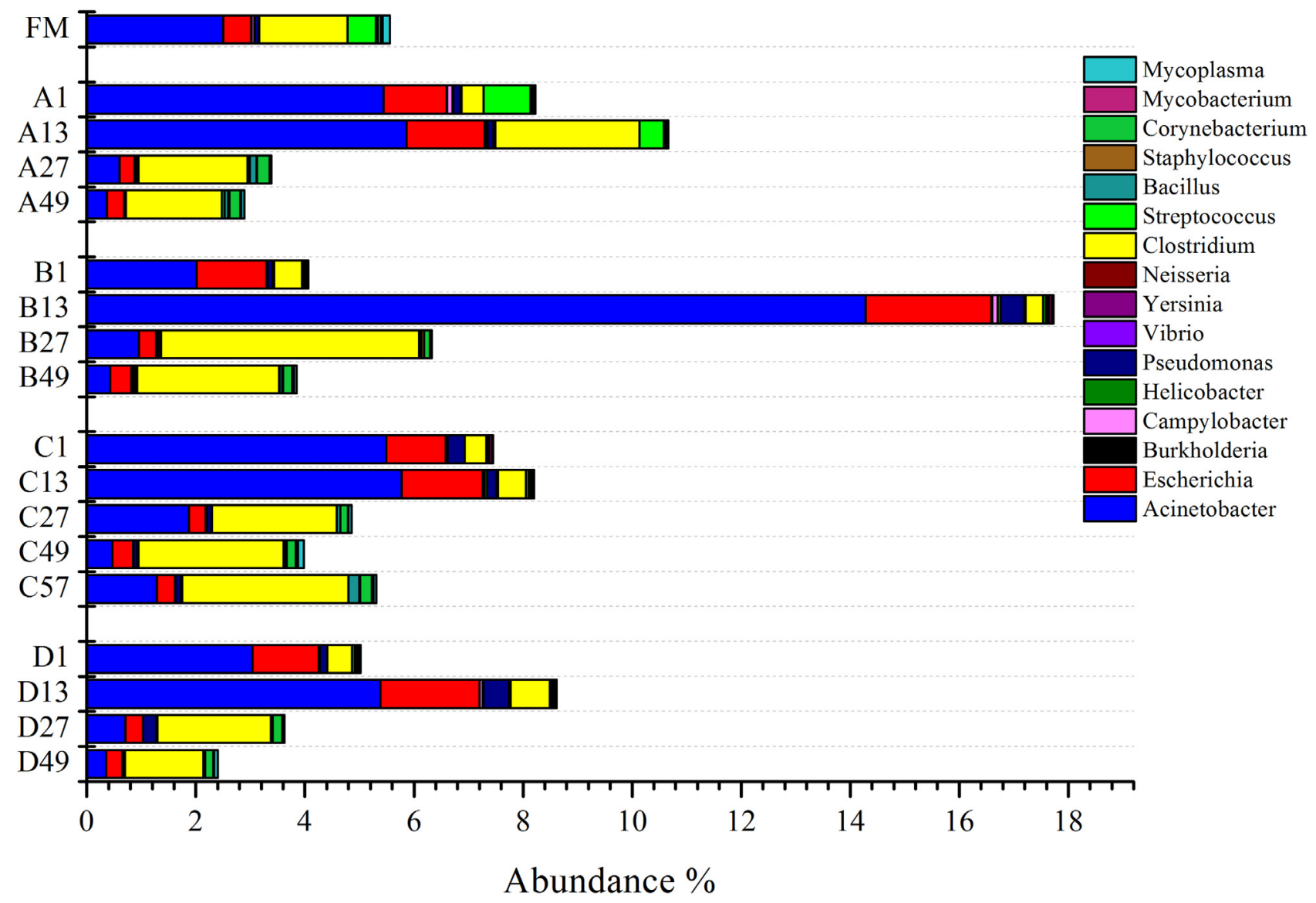

Fig. 3. Potential pathogens change during the swine manure anaerobic digestion of A, B, C and D tests (genus). 


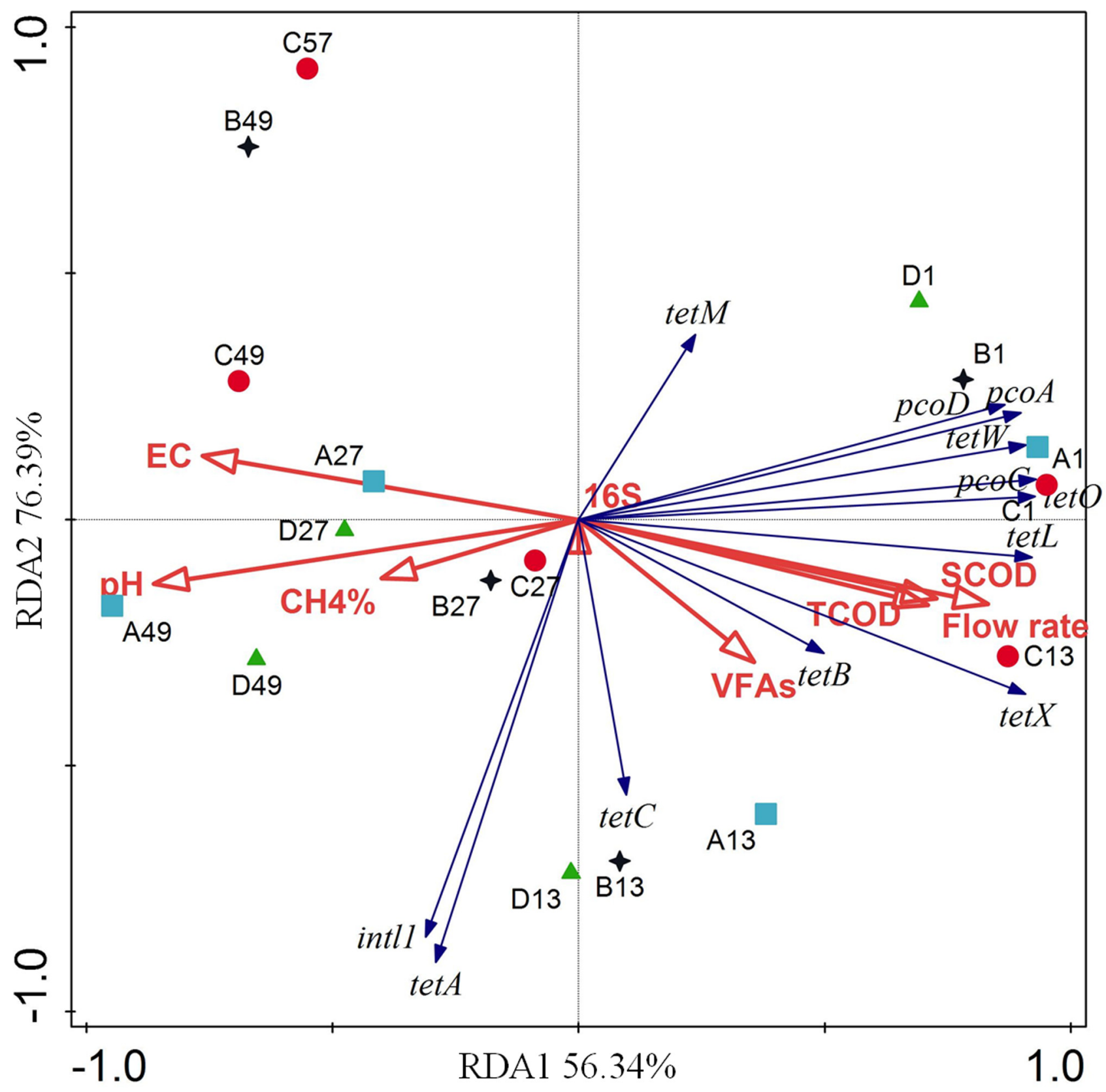

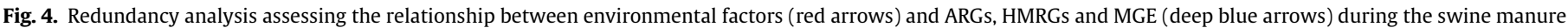

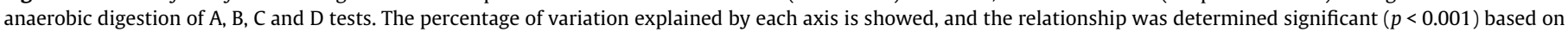
499 permutations. (For interpretation of the references to colour in this figure legend, the reader is referred to the web version of this article.)

(A49, B49, C57, D49), respectively. The result from Pearson correlation showed that it presented a significant negative correlation with the predominant ARGs (tetO, tetX, tetL, tetW) and HMRGs (pcoA, pcoC, pcoD) (Table 5, Fig. 5). It was assumed that Treponema might have a competitive relationship with the host bacteria of the predominant ARGs. During anaerobic digestion, Treponema took over the ecological niche from the dominant bacteria such as Prevotella and Bacteroides in the fresh swine manure and might result in the corresponding resistance genes decreasing.

It seemed that CTC + $\mathrm{Cu}$ had a great influence on the Treponema, which varied differently comparing to the other groups. In the control, CTC and Cu spiked tests, Treponema increased gradually along with anaerobic digestion, and reached to the maximum values in the end; however, in the CTC + Cu test, it increased and reached to the maximum (28.78\%) on the 27 th day, and then decreased to a relatively low value (10.56\%) in the end. Poirier et al. (2016) demonstrate that Treponema is a kind of potential syntrophic microorganisms with methanogens, which fluctuates along with the concentration of total ammonia nitrogen (TAN) in anaerobic digestion. Therefore, to some extent, the abundance of Treponema signified the process of anaerobic digestion, which the maximum abundance implied the termination of anaerobic digestion. In this case, CTC $+\mathrm{Cu}$ group reached to the termination of anaerobic digestion on the 27th day, while the biogas production had almost stopped $(1.7 \mathrm{~mL} /$ day $)$. It was hypothesis that Treponema competed with some of the ARGs host bacteria, in the final few days of CTC $+\mathrm{Cu}$ test, abundance of Treponema decreased dramatically from $28.78 \%$ to $10.56 \%$, oppositely, several tet genes and MEG increased, including tetA, tetO, tetX, tetL, tet $\mathrm{W}$, intI 1 , especially tetA and intI 1 ascended dramatically. However, further study is needed to reveal the real reason. 


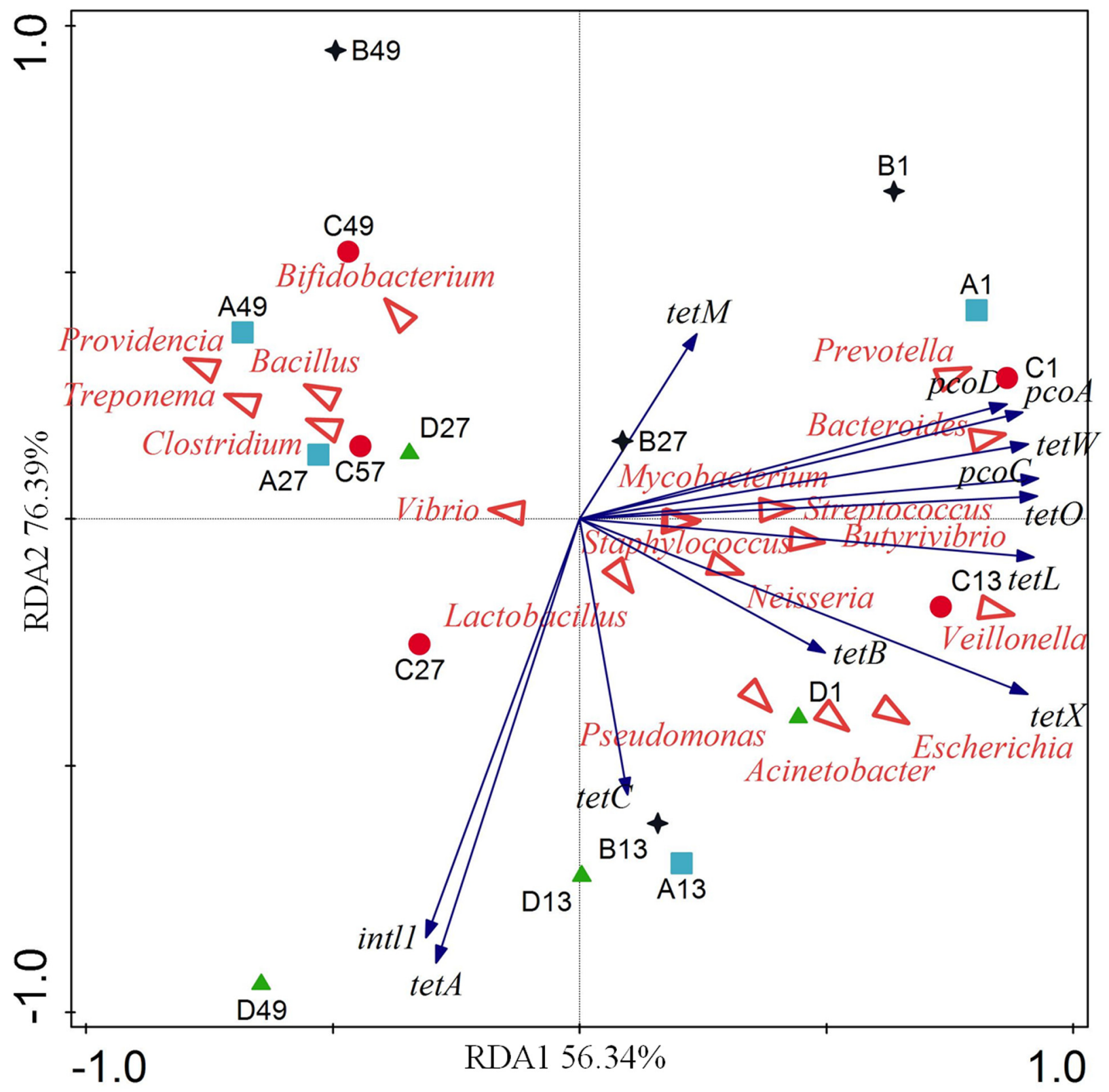

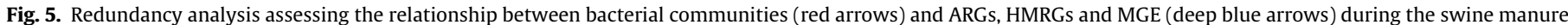

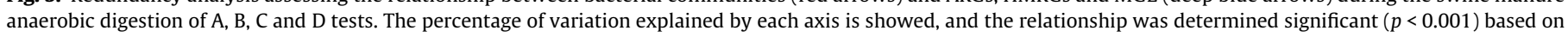
499 permutations. (For interpretation of the references to colour in this figure legend, the reader is referred to the web version of this article.)

16 potential pathogenic bacteria (from 30 potential pathogens based on http://www.mgc.ac.cn/cgi-bin/VFs/jsif/main.cgi) were detected and showed in the Fig. 3, and more detailed information about the Pearson correlations between the most abundant bacteria, the potential pathogens at genus level and ARGs, HMRGs, MEG were shown in the Table 5 , red characters represented the potential pathogens. The total potential pathogens detected in this study took on a decreasing trend among the four tests, which was $5.56 \%$ in the fresh swine manure, and decreased to $2.89 \%, 3.85 \%, 5.31 \%$ and $2.40 \%$ in the control, CTC, $\mathrm{Cu}$ and CTC $+\mathrm{Cu}$ tests, respectively. This implied that anaerobic digestion could somehow eliminate the potential pathogens.

Acinetobacter was the most abundant genus in the beginning (2\%-5\%) and decreased most obviously in the course of anaerobic digestion. TetC and tetX showed a positive correlation with
Acinetobacter, tetX declined down largely, tetC fluctuated and was barely reduced in the end of the tests. Previous studies reported that tetA has been distributed in Acinetobacter, Escherichia, Pseudomonas (Chopra and Roberts, 2001), however, it did not exhibit any positive correlation with these bacteria in this study. Actually, tetA and intI 1 did not show any significant correlation with the most abundant bacteria and the potential pathogens listed in the Table 5.

Escherichia accounted for approximately $1.2 \%$ in the beginning and exhibited an evidently decreasing trend among the four tests as well (A49: 0.32\%; B49: 0.39\%; C57: 0.33\%; D49: 0.30\%). TetL and tetX showed a positive correlation with Escherichia, which both of them decreased largely. It was speculation that Escherichia contributed to the reduction of tetL and tetX. Clostridium was barely removed and kept a relatively stable level (around 2\%) during the 
Table 5

Pearson Correlations among ARGs, HMRGs, MGE and host genera $\left(\mathrm{R}^{2}\right)$.

\begin{tabular}{|c|c|c|c|c|c|c|c|c|c|c|c|c|c|}
\hline Genus & tet $\mathrm{A}$ & tet $\mathrm{C}$ & tet $\mathrm{O}$ & tet $\mathrm{M}$ & tet $\mathrm{X}$ & tet $\mathrm{L}$ & tet $\mathrm{W}$ & tet $\mathrm{B}$ & pcoA & pcoC & pcoD & Intl 1 & $16 \mathrm{~s}$ \\
\hline Prevotella & -0.200 & -0.246 & $0.828 * *$ & 0.148 & 0.397 & $0.555^{*}$ & $0.825^{* *}$ & -0.017 & $0.902 * *$ & $0.975^{* *}$ & $0.932 * *$ & -0.330 & 0.395 \\
\hline Bacteroides & -0.192 & -0.104 & $0.788 * *$ & 0.071 & $0.560^{*}$ & $0.587^{*}$ & $0.797 * *$ & -0.042 & $0.856^{* *}$ & $0.914 * *$ & $0.864 * *$ & -0.302 & $0.496 *$ \\
\hline Acinetobacter & -0.120 & $0.590^{*}$ & 0.238 & -0.179 & $0.613 * *$ & 0.409 & 0.298 & 0.148 & 0.296 & 0.296 & 0.275 & -0.005 & 0.397 \\
\hline Escherichia & -0.130 & 0.480 & 0.277 & -0.182 & $0.718 * *$ & $0.497^{*}$ & 0.347 & 0.251 & 0.374 & 0.358 & 0.324 & 0.001 & 0.416 \\
\hline Pseudomonas & -0.176 & 0.317 & 0.120 & -0.311 & 0.386 & 0.230 & 0.125 & 0.418 & 0.197 & 0.220 & 0.224 & 0.063 & 0.141 \\
\hline Providencia & 0.167 & -0.337 & $-0.568 *$ & 0.211 & $-0.710^{* *}$ & $-0.584^{*}$ & $-0.586^{*}$ & -0.329 & $-0.586^{*}$ & $-0.572 *$ & $-0.534^{*}$ & 0.086 & $-0.580^{*}$ \\
\hline Vibrio & 0.037 & -0.071 & -0.395 & -0.244 & 0.092 & 0.122 & -0.259 & 0.001 & -0.217 & -0.368 & -0.336 & 0.124 & -0.342 \\
\hline Neisseria & -0.176 & 0.251 & 0.006 & -0.167 & 0.366 & 0.342 & 0.116 & 0.035 & 0.183 & 0.175 & 0.127 & -0.104 & -0.099 \\
\hline Clostridium & -0.065 & 0.178 & -0.267 & 0.338 & $-0.645^{* *}$ & $-0.534^{*}$ & -0.348 & 0.208 & $-0.556^{*}$ & $-0.606^{* *}$ & $-0.500^{*}$ & 0.037 & -0.014 \\
\hline Lactobacillus & 0.115 & -0.348 & 0.041 & $-0.556^{*}$ & 0.199 & 0.252 & 0.064 & -0.018 & 0.352 & 0.230 & 0.354 & 0.092 & -0.115 \\
\hline Streptococcus & -0.082 & 0.164 & $0.524^{*}$ & 0.181 & 0.252 & 0.169 & 0.471 & 0.033 & 0.325 & 0.434 & 0.390 & -0.047 & $0.596^{*}$ \\
\hline Bacillus & -0.161 & -0.136 & -0.390 & 0.095 & $-0.529 *$ & -0.410 & -0.440 & -0.203 & -0.350 & -0.401 & -0.295 & -0.110 & -0.298 \\
\hline Staphylococcus & -0.009 & 0.024 & 0.256 & 0.095 & 0.323 & 0.245 & 0.292 & 0.419 & 0.025 & -0.074 & -0.079 & -0.071 & 0.036 \\
\hline Veillonella & -0.162 & 0.146 & $0.557^{*}$ & -0.119 & $0.817 * *$ & $0.694^{* *}$ & $0.626^{* *}$ & 0.168 & $0.685^{* *}$ & $0.674 * *$ & $0.616^{* *}$ & -0.156 & 0.445 \\
\hline Butyrivibrio & -0.175 & -0.160 & 0.249 & -0.146 & $0.789 * *$ & $0.574^{*}$ & 0.345 & -0.183 & 0.419 & 0.304 & 0.297 & -0.328 & 0.086 \\
\hline Bifidobacterium & -0.184 & -0.304 & -0.375 & -0.023 & -0.303 & -0.218 & -0.354 & -0.256 & -0.115 & -0.223 & -0.107 & -0.212 & -0.385 \\
\hline Mycobacterium & -0.004 & 0.160 & 0.021 & -0.133 & 0.342 & 0.453 & 0.175 & -0.206 & 0.401 & 0.263 & 0.382 & -0.013 & 0.098 \\
\hline Treponema & -0.069 & -0.280 & $-0.571 *$ & -0.181 & $-0.554^{*}$ & $-0.512 *$ & $-0.594 *$ & -0.228 & $-0.581^{*}$ & $-0.603 *$ & $-0.527^{*}$ & -0.035 & $-0.580^{*}$ \\
\hline Burkholderia & -0.143 & 0.292 & -0.227 & $0.617 * *$ & -0.209 & -0.257 & -0.215 & -0.162 & -0.351 & -0.298 & -0.321 & -0.167 & -0.155 \\
\hline Campylobacter & -0.136 & 0.327 & 0.427 & -0.145 & $0.529 *$ & 0.258 & 0.406 & 0.261 & 0.282 & 0.379 & 0.300 & -0.070 & 0.367 \\
\hline Helicobacter & -0.019 & $0.495^{*}$ & 0.149 & -0.042 & $0.679 * *$ & $0.552 *$ & 0.299 & 0.052 & 0.225 & 0.140 & 0.132 & 0.018 & 0.270 \\
\hline Yersinia & -0.014 & $0.490^{*}$ & 0.110 & 0.443 & 0.009 & -0.011 & 0.079 & -0.045 & 0.011 & 0.056 & 0.064 & 0.140 & $0.660 * *$ \\
\hline Corynebacterium & 0.070 & -0.301 & $-0.630 * *$ & 0.054 & $-0.741 * *$ & $-0.651^{* *}$ & $-0.681 * *$ & -0.345 & $-0.652 * *$ & $-0.645^{* *}$ & $-0.603^{*}$ & 0.026 & $-0.636^{* *}$ \\
\hline Mycoplasma & 0.197 & -0.360 & $-0.501^{*}$ & -0.358 & $-0.563^{*}$ & $-0.592 *$ & $-0.569 *$ & -0.284 & -0.472 & -0.478 & -0.457 & 0.058 & $-0.582 *$ \\
\hline
\end{tabular}

**: Correlation is significant at the 0.01 level $(p<0.01)$; *: Correlation is significant at the 0.05 level $(p<0.05)$.

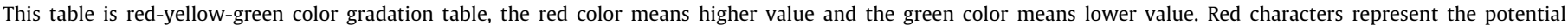
pathogens according to (http://www.mgc.ac.cn/cgi-bin/VFs/jsif/main.cgi).

anaerobic digestion. TetX, tetL and pcoA, pcoC, pcoD showed a significant negative correlation with Clostridium. Other potential pathogens such as Corynebacterium and Mycoplasma also presented a significant negative correlation with the predominant ARGs and HMRGs during the swine manure anaerobic digestion, which indicated that they might compete with the host bacteria of ARGs and HMRGs. It was notable that Corynebacterium obviously increased during the swine manure anaerobic digestion and accounted for approximately $0.18 \%$ in the end. The previous study demonstrated that Corynebacterium had a significant positive correlation with the tet and pco genes during the swine manure composting (Wang et al., 2016). These opposite results indicated that the relationship between ARGs and bacteria was complicated and different operated conditions or different technologies could impact both of them variations. Certain bacteria might be host of ARGs in one condition, but might not be the host of the same ARGs in the other condition. Therefore, the relationship between the host bacteria and ARGs needs further studies. 


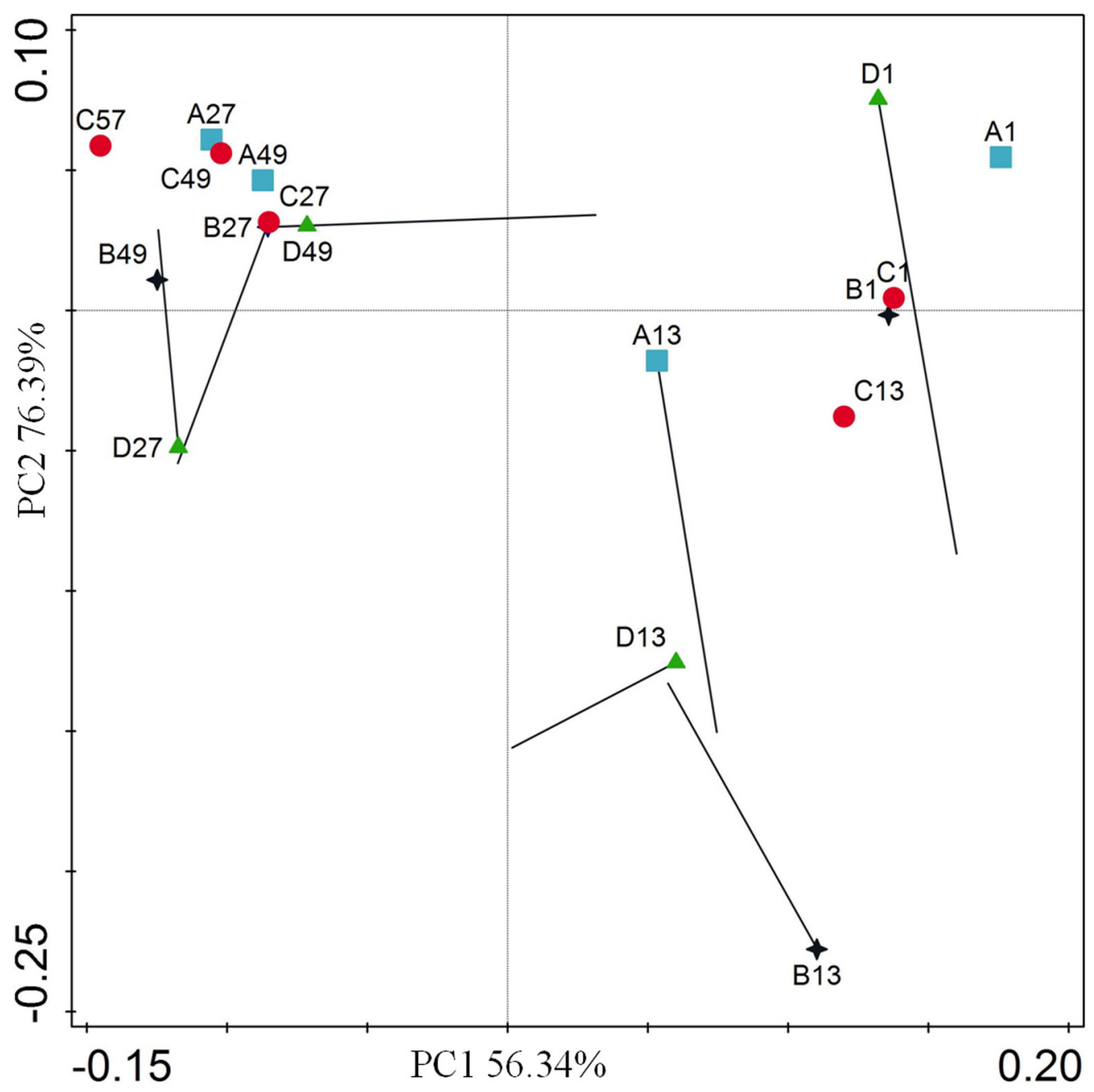

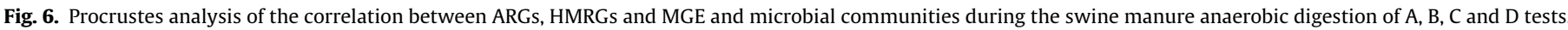
The percentage of variation explained by each axis is showed, and the relationship was determined significant $(p<0.001)$ based on 499 permutations.

Procrustes analysis was conducted by rotating the ordination of changes in the microbial communities to match the profiles of resistance genes based on a PCA analysis (Fig. 6), and the results indicated that most of the resistance genes and bacterial communities clustered during the swine manure anaerobic digestion. The explanatory variables accounted for $44.6 \%$, and the correlation between the first two axes was strongly positive $(\mathrm{R}=0.91$ and 0.42 , respectively). Therefore, evolutions in the microbial communities' structures along with the swine manure anaerobic digestion contributed evidently to the resistance gene profiles.

\section{Conclusions}

The predominant ARGs (tetO, tetW, tetX, tetL) and HMRGs ( $p c o \mathrm{~A}$, $p c o C, p c o \mathrm{D}$ ) in fresh swine manure could be effectively eliminated (approximately $1.00 \log$ copies/g TS) through mesophilic anaerobic digestion. Addition of CTC, $\mathrm{Cu}$ and $\mathrm{CTC}+\mathrm{Cu}$ could impact the changes of ARGs, to some extent, especially CTC + Cu spiked could obviously inhibit the removal of ARGs; and affect shaping of bacterial communities during the anaerobic digestion. It is better to control the usage of antibiotics and heavy metals in swine industries as feed additive to better control the pollution of resistance genes.

\section{Acknowledgements}

This work is financially supported by Special Fund for Agroscientific Research in the Public Interest of China (No. 201303091), the National Major Science \& Technology Projects for Water Pollution Control and Management of China (No. 2015ZX07203-007), and the National Natural Science Foundation of China (No. 21577161; No. 21077122; No. 41501513).

\section{Appendix A. Supplementary data}

Supplementary data associated with this article can be found, in the online version, at http://dx.doi.org/10.1016/j.biortech.2017.03. 134.

\section{References}

Agersø, Y., Sandvang, D., 2005. Class 1 integrons and tetracycline resistance genes in Alcaligenes, Arthrobacter, and Pseudomonas spp. isolated from pigsties and manured soil. Appl. Environ. Microbiol. 71 (12), 7941-7947.

Baker-Austin, C., Wright, M.S., Stepanauskas, R., McArthur, J.V., 2006. Co-selection of antibiotic and metal resistance. Trends Microbiol. 14 (4), 176-182.

Berglund, Björn., 2015. Environmental dissemination of antibiotic resistance genes and correlation to anthropogenic contamination with antibiotics. Infect. Ecol. Epidemiol. 5, 28564. 
Caporaso, J.G., Kuczynski, J., Stombaugh, J., Bittinger, K., Bushman, F.D., Costello, E.K. Fierer, N., Pena, A.G., Goodrich, J.K., Gordon, J.I., 2010. QIIME allows analysis of high-throughput community sequencing data. Nat. Methods 7 (5), 335-336.

Chopra, I., Roberts, M., 2001. Tetracycline antibiotics: mode of action, applications, molecular biology, and epidemiology of bacterial resistance. Microbiol. Mol. Biol. Rev. 65 (2), 232-260.

Edgar, R.C., Haas, B.J., Clemente, J.C., Quince, C., Knight, R., 2011. UCHIME improves sensitivity and speed of chimera detection. Bioinformatics 27 (16), 2194-2200.

Heuer, H., Schmitt, H., Smalla, K., 2011. Antibiotic resistance gene spread due to manure application on agricultural fields. Curr. Opin. Microbiol. 14 (3), 236243.

Kemper, N., 2008. Veterinary antibiotics in the aquatic and terrestrial environment. Ecol. Indic. 8 (1), 1-13.

Koike, S., Krapac, I., Oliver, H., Yannarell, A., Chee-Sanford, J., Aminov, R., Mackie, R. 2007. Monitoring and source tracking of tetracycline resistance genes in lagoons and groundwater adjacent to swine production facilities over a 3-year period. Appl. Environ. Microbiol. 73 (15), 4813.

Kumar, K., Gupta, S., Baidoo, S., Chander, Y., Rosen, C., 2005. Antibiotic uptake by plants from soil fertilized with animal manure. J. Environ. Qual. 34 (6), 2082 2085.

LaPara, T.M., Diehl, D.L., 2010. Effect of temperature on the fate of genes encoding tetracycline resistance and the integrase of class 1 integrons within anaerobic and aerobic digesters treating municipal wastewater solids. Environ. Sci. Technol. 44 (23), 9128-9133.

Liu, M., Zhang, Y., Yang, M., Tian, Z., Ren, L., Zhang, S., 2012. Abundance and distribution of tetracycline resistance genes and mobile elements in an oxytetracycline production wastewater treatment system. Environ. Sci. Technol. 46 (14), 7551-7557.

Mackie, R.I., Koike, S., Krapac, I., Chee-Sanford, J., Maxwell, S., Aminov, R.I., 2006. Tetracycline residues and tetracycline resistance genes in groundwater impacted by swine production facilities. Anim. Biotechnol. 17 (2), 157-176.

Martinez, J., 2008. Antibiotics and antibiotic resistance genes in natural environments. Science 321, 365-367. http://dx.doi.org 10.1126/science. 1159483.

Martinez, J., Coque, T.M., Baquero, F., 2014. What is a resistance gene? Ranking risk in resistomes. Nat. Publ. Gr., 1-8 http://dx.doi.org/10.1038/nrmicro3399.

Mei, R., Narihiro, T., Nobu, M.K., Liu, W.T., 2016. Effects of heat shocks on microbia community structure and microbial activity of a methanogenic enrichment degrading benzoate. Lett. Appl. Microbiol. 63 (5), 356-362.

Molla, B., Miko, A. Pries, K., Hildebrandt, G., Kleer, J., Schroeter, A., Helmuth, R. 2007. Class 1 integrons and resistance gene cassettes among multidrug resistant Salmonella serovars isolated from slaughter animals and foods of animal origin in Ethiopia. Acta Trop. 103 (2), 142-149.
Nicholson, F., Chambers, B., Williams, J., Unwin, R., 1999. Heavy metal contents of livestock feeds and animal manures in England and Wales. Bioresour. Technol. 70 (1), 23-31.

Olsvik, B., Olsen, I., Tenover, F.C., 1995. Detection of tet(M) and tet(O) using the polymerase chain reaction in bacteria isolated from patients with periodontaldisease. Oral Microbiol. Immun. 10 (2), 87-92.

Pal, C., Bengtsson-Palme, J., Kristiansson, E., Larsson, D.G.J., 2015. Co-occurrence of resistance genes to antibiotics, biocides and metals reveals novel insights into their co-selection potential. Bmc Genomics 16.

Poirier, S., Desmond-Le Quemener, E., Madigou, C., Bouchez, T., Chapleur, O., 2016. Anaerobic digestion of biowaste under extreme ammonia concentration: Identification of key microbial phylotypes. Bioresour. Technol. 207, 92-101.

Roberts, M.C., 2005. Update on acquired tetracycline resistance genes. FEMS Microbiol. Lett. 245 (2), 195-203.

Sarmah, A.K., Meyer, M.T., Boxall, A., 2006. A global perspective on the use, sales, exposure pathways, occurrence, fate and effects of veterinary antibiotics (VAs) in the environment. Chemosphere 65 (5), 725-759.

Sui, Q.W., Zhang, J.Y., Chen, M.X., Tong, J., Wang, R., Wei, Y.S., 2016. Distribution of antibiotic resistance genes (ARGs) in anaerobic digestion and land application of swine wastewater. Environ. Pollut. 213, 751-759.

Toleman, M.A., Bennett, P.M., Walsh, T.R., 2006. ISCR elements: novel genecapturing systems of the 21st century? Microbiol. Mol. Biol. Rev. 70 (2), 296316.

Wang, R., Zhang, J.Y., Sui, Q.W., Wan, H.F., Tong, J., Chen, M.X., Wei, Y.S., Wei, D.B., 2016. Effect of red mud addition on tetracycline and copper resistance genes and microbial community during the full scale swine manure composting. Bioresour. Technol. 216, 1049-1057.

Woese, C.R., Kandler, O., Wheelis, M.L., 1990. Towards a natural system of organisms- proposal for the domains archaea, bacteria, and eucarya. Proc. Natl. Acad. Sci. U.S.A. 87 (12), 4576-4579.

Wu, N., Qiao, M., Zhang, B., Cheng, W.-D., Zhu, Y.-G., 2010. Abundance and diversity of tetracycline resistance genes in soils adjacent to representative swine feedlots in China. Environ. Sci. Technol. 44 (18), 6933-6939.

Wu, Y., Cui, E., Zuo, Y., Cheng, W., Rensing, C., Chen, H., 2016. Influence of two-phase anaerobic digestion on fate of selected antibiotic resistance genes and class I integrons in municipal wastewater sludge. Bioresour. Technol. 211, 414-421.

Zhang, J.Y., Chen, M.X., Sui, Q.W., Tong, J., Jiang, C., Lu, X.T., Zhang, Y.X., Wei, Y.S., 2016. Impacts of addition of natural zeolite or a nitrification inhibitor on antibiotic resistance genes during sludge composting. Water Res. 91, 339-349.

Zhang, W. Wei, Q., Wu, S., Qi, D., Li, W., Zuo, Z., Dong, R., 2014. Batch anaerobic codigestion of pig manure with dewatered sewage sludge under mesophilic conditions. Appl. Energ. 128, 175-183. 